\title{
Sustainability Indicators of Biomass Production in Agroforestry Systems
}

\author{
Naresh Thevathasan ${ }^{1, *}$, Andrew Gordon ${ }^{1}$, Jamie Simpson ${ }^{1}$, Xiaobang Peng ${ }^{2}$, Salim Silim ${ }^{3}$, \\ Raju Soolanayakanahally ${ }^{4}$ and Henry de Gooijer ${ }^{4}$
}

${ }^{1}$ School of Environmental Sciences, University of Guelph, Guelph, Ontario, N1G 2 W1 Canada; ${ }^{2}$ Department of
Biological and Medical Engineering, ShangLuo University, ShangLuo, Shaanxi 726000, PR China; ${ }^{3}$ Agri-Green Tech-
nologies Secretariat, Agri-Environment Services Branch Agriculture and Agri-Food Canada, Ottawa, Ontario K1A OC6,
Canada; ${ }^{4}$ Agroforestry Development Centre, Agriculture and Agri-Food Canada, Indian Head, SK, SOG 2 K0, Canada

\begin{abstract}
Production of biomass for bioenergy will depend on the sustainability of the production resource-base: the soil, water, air and the diversity of the ecosystem as a whole. For soil, potential sustainability indicators, including soil nitrogen and phosphorus, total organic matter, components associated with soil erosion and bulk density are discussed. Indicators related to the water resource water quality, water availability index, nitrate levels in water and biological oxygen demand are also discussed. Greenhouse gases and their sequestration potentials are discussed for maintaining atmospheric air quality. For biodiversity, a biodiversity index and soil biota index were selected as potential indicators. In addition to the production resource-base, the paper also discusses the importance of economic and social sustainability indices. To summarize, we are suggesting that a common method of visualizing the above indicated indices is to generate amoeba diagrams. This paper also provides a review on the term 'sustainability' and specific indicators, with metrics where possible, are described as candidates for inclusion as potential indicators appropriate for agroforestry based bioenergy systems in Canada. Three agroforestry based bioenergy systems are described and specific indicators are discussed within the bounds of these systems.
\end{abstract}

Keywords: Agroforestry, bioenergy, poplar, sustainability indicators, willow, woody biomass.

\section{INTRODUCTION}

The deliberate introduction of trees into agricultural or pasture lands, in an agroforestry format (low density of trees with crops and/or animals), has resulted in diversified products and ecosystem services [1,2]. These ecosystem services are derived mainly as a result of integrating the perennial tree component into the agro-ecosystems. In Short Rotation Woody Crop (SRWC) production systems, fast growing trees (e.g. willow (Salix spp.), and poplar (Populus spp.)) are integrated into marginal or high quality agricultural lands at very high densities, 15,000 to 20,000 trees per hectare. It is therefore safe to assume that similar ecosystem services as observed in agroforestry systems can also be derived in SRWC production systems due to the presence of perennial trees. Therefore, sustainability indicators associated with the production resource-base for both systems would be common indicators but the quantitative values associated with a given indicator will differ for both systems due to varying tree densities.

Before developing sustainability indicators, the term 'sustainability' must be defined; however, this is not a term that has an easy scientific definition. Rather it is inherently imbued by the bias of the speaker. There are those that revile

*Address correspondence to this author at the School of Environmental Sciences, University of Guelph, Guelph, Ontario, N1G 2W1 Canada;

Tel: 519-824-4120 x 52565; Fax: 519-837-0756;

E-mail: nthevath@uoguelph.ca the common usage of the term using such adjectives as 'empty', 'condescending' and 'paternalistic' [3]. In 1987, the UN presented Our Common Future (a.k.a. The Brundtland Report) where it was stated that 'Sustainable development is development that meets the needs of the present without compromising the ability of future generations to meet their own needs' [4]. This is perhaps the most quoted passage in the literature related to sustainability. Despite the number of occasions where this definition is quoted or referred to, there remains disagreement. Many authors echo the theme of the Brundtland report $[5,6]$ while others promote an alternate view, "the only sustainable agriculture is profitable agriculture" [7].

Perhaps part of the problem in providing an acceptable definition is the ad hoc manner in which sustainability has been assessed. To date, there are no universally accepted methods of assessment, let alone a standardized set of indicators, although the International Organization for Standardization (ISO) is currently developing a set specific to the bioenergy sector (ISO/TC248 Sustainability criteria for bioenergy). Some even argue for region specific indicator sets [8], which could result in even greater confusion.

This paper provides a good review on the term "sustainability" by providing different approaches taken to define the term "sustainability" in any given production system. The paper also emphasizes the need to include economic and social dimensions along with environmental considerations when defining sustainability. Given these three dimensions 
(economy, social and environment), the paper describes in detail the development of potential sustainability indicators under each dimension associated with SRWC and agroforestry land-use systems in Canada.

\section{CONCEPT OF SUSTAINABILITY}

What is generally accepted is that 'sustainability' has three components: economic, social and environment. Often these are referred to as the three pillars while others prefer to view these in a hierarchal fashion where economic sustainability is only achievable if societal sustainability exists. These in turn are entirely reliant on the environment to provide goods and services over an extended period of time. Although these two views of sustainability seem to possess only a minor difference, it does result in two competing paradigms of sustainability: the wealth approach and the mosaic approach $[9,10]$.

The wealth approach requires a full appreciation for the value of both built and natural capital and that future generation should inherit assets at least equal to the current value [9]. The wealth approach can be further dissected into two camps of weak and strong sustainability. Weak sustainability allows for the substitution of man-made and natural capital. This paradigm treats natural resources as a liquid asset. This concept also presupposes that there will continue to be technological and/or social advancements that can compensate for losses of our natural capital. Alternatively, strong sustainability requires that natural capital be conserved thus ensuring resource availability for future generations [11].
Under weak sustainability, the transfer of capital or revenue from the site of production to purchase resources in an effort to compensate for existing production site limitations or loss of capital due to export is acceptable. A life cycle analysis (LCA) of such a scenario will obviously reveal a loss of capital from another area. This creates an interesting conundrum. For example, rock phosphate is mined for the benefit of high output agriculture. Where this resource is not conserved, either exported with the crop or lost due to erosion, replacement is required. This requires further mining of a finite resource. However, managing an agronomic system without the requirement for exogenous inputs renders the value of those potential inputs (e.g. rock phosphate) essentially zero. Under the paradigm of strong sustainability, the management system would conserve as much phosphorus as possible minimizing the requirement for external inputs, delaying the depletion of such resources to some time in the future.

The mosaic approach is essentially the same as the three pillars mentioned earlier. Ecological sustainability requires maintenance of ecological processes. Feasibility is the key concept in economic sustainability, and social acceptability is required to create the social pillar [11]. The Helmholtz concept is based on an "understanding of sustainability whose central ethical postulate is justice" [11]. This concept is set apart from traditional models of sustainability and establishes somewhat different goals, specifically "(1) securing human existence, (2) maintaining society's productive potential and (3) preserving society's options for development and

Table 1. Sustainability indicators selected for an expert survey (rankings in brackets), adapted from Buchholz et al. (2009).

\begin{tabular}{|l|l|l|}
\hline \multicolumn{1}{|c|}{ Social } & \multicolumn{1}{|c|}{ Economic } & \multicolumn{1}{c|}{ Environmental } \\
\hline \hline Compliance with laws [8] & Employment generation [22] & Adaptation capacity [13] \\
\hline Food security [11] & Microeconomic sustainability [7] & Energy balance [2] \\
\hline $\begin{array}{l}\text { Land available for activities other than food } \\
\text { production [32] }\end{array}$ & Macroeconomic sustainability [27] & Natural resource efficiency [6] \\
\hline Participation [participatory democracy] [4] & Economic stability [17] & Species protection [18] \\
\hline Cultural acceptability [28] & & Ecosystem protection [9] \\
\hline Social cohesion [31] & & Ecosystem connectivity [25] \\
\hline Human rights [27] & & Crop diversity [14] \\
\hline Working conditions [15] & & Exotic species [30] \\
\hline Respect for minorities [29] & & Use of genetically modified organisms [24] \\
\hline Standard of living [33] & & Use of chemicals [19] \\
\hline Property rights [22] & & Soil protection [3] \\
\hline Planning [16] & & Land use change [23] \\
\hline Monitoring of criteria performance [10] & & Water management [5] \\
\hline Visual impacts [35] & & Waste management [12] \\
\hline Noise impacts [34] & & Greenhouse gas balance [1] \\
\hline & Hazardous emissions (other than GHG's) [20] \\
\hline
\end{tabular}


action." While this is a very anthropocentric starting point, the concept does not put limits on non-human values. This method of developing a sustainability assessment program adheres to the principles described in the Brundtland Report. The Helmholtz concept further operationalizes rules for sustainability. From these rules, indicators may be developed.

The Bellagio Principles provide a guiding framework for a sustainability assessment program [12; http://www.iisd.org/measure/principles/progress/bellagio_full.asp]. Similar to the Helmholtz Principles, these 10 principles guide the process of developing effective goals, objectives and indicators for assessing sustainability. The 10 principles are: Guiding principles and goals, holistic perspective, essential elements, adequate scope, practical focus, openness, effective communication, broad participation, ongoing assessment and institutional capacity. Of particular note is the requirement for ongoing assessment. While overarching goals are likely to remain the same during the life of a project, our knowledge and understanding at a systems level is sure to improve. This will in all likelihood result in changes in how we approach certain aspects of the assessment program.

Taking a more specific approach to agricultural sustainability, Zahm et al. (2008) developed IDEA (Indicateurs de Durabilité des Exploitations Agricoles or Farm Sustainability Indicators) [13]. This system is based on key concepts of sustainable agriculture as detailed by [14]: viable, livable, transferable and reproducible. These are essentially equivalent to the more generalized 3 pillars: economic, social and environmental. Buchholz [15] performed a review of the literature related to the development of sustainability indicators for bioenergy systems and created a list of the most common criteria used to make an assessment. They followed up on this effort by conducting a survey of experts from various sectors within the bioenergy field, which resulted in a ranking of the criteria.

Several of these criteria function beyond the farm gate. For example, macro-economic sustainability incorporates all practices from crop production to energy production and the impact on global energy markets. Micro-economic criteria can be assessed within the farm gate. The literature does not suggest a critical metric for sustainability at a microeconomic level. However, logically, any production system that tips the farm balance sheet into a negative position is unsustainable.

Only two criteria were selected by more than half of respondents to the survey as critical to any bioenergy assessment scheme: Greenhouse Gas (GHG) balance and energy balance. Both of these criteria would have to be assessed throughout the life cycle of a bioenergy system. However, GHG balance can be assessed within the farm gate and compared to alternative systems of crop production. Participation, a social indicator, ranked high among respondents indicating the demand for inclusivity among the variety of stakeholders in the decision making process. Stakeholder participation at both the policy and planning stages is required to ensure operational compliance, fundamental to the success of achieving stated goals.

In this survey visual and noise impacts ranked at the bottom of the list. It may be that the survey respondents recog- nize that shifting cropping practices would have little effect on these criteria among the local population. As such, it would be difficult to develop an indicator(s) that could effectively measure a response from neighbours or the public and thus would not be discriminatory in evaluating sustainability. Similarly, cultural acceptability ranks low. Perhaps because there are few arguments against a system that can show economic and environmental benefits, if that is indeed the case.

Agroforestry practices that are currently being researched in North America include shelterbelts, windbreaks, silvopastoral systems, forest farming systems, integrated riparian forest systems, and tree-based intercropping systems [16-18]. Over the past 25 years, investigations on tree-based intercropping systems in southern Ontario have discovered several complementary biophysical interactions associated with this land-use system [18]. In this context, several of the criteria provided in this list will be useful to develop sustainability indicators associated with temperate agroforestry systems. This paper also discusses indicators associated with biomass production in agroforestry systems in addition to biomass production sustainability indicators associated with SRWC systems.

\section{INDICATORS FOR MONITORING SRWC SUSTAIN- ABILITY}

\section{Environmental Air Indices}

\section{GHG Emissions}

Measuring GHG emissions and sequestration are obvious measures of sustainability. Zero net emissions are good while net sequestration is better. A system that is a net emitter may be deemed unsustainable. The math is not so simple and systems that contribute relatively small amounts of net GHG production may be better options where other benefits exist, thus more sustainable. There still exists some uncertainty as to the ability of the planet to absorb $\mathrm{CO}_{2}$ and other GHG's without substantive changes to ecosystem processes. While the science continues to evolve the general consensus among researchers, if not policy makers, is that action must be taken to reduce GHG emissions.

The contributing components to a GHG index include $\mathrm{CO}_{2}, \mathrm{~N}_{2} \mathrm{O}, \mathrm{HFC}$ 's, PFC's and $\mathrm{CH}_{4}$. HFC's and PFC's do not need to be accounted for within the farm gate as they are generally derived from industrial sources and cooling systems. $\mathrm{CO}_{2}$ and $\mathrm{N}_{2} \mathrm{O}$ have been suggested as the main components to be monitored [19] given that the flux of both compounds is strongly correlated to management practices [2022]. $\mathrm{N}_{2} \mathrm{O}$ may be produced directly through the processes of denitrification and nitrification or indirectly by conversion of deposited $\mathrm{NO}_{\mathrm{x}}$ and $\mathrm{NH}_{3}$ as well as through combustion. Soil nitrogen in excess of crop demand can leach into ground and surface water where it can undergo conversion to $\mathrm{N}_{2} \mathrm{O}$ as well in the presence of soluble $\mathrm{C}$.

McBride et al. [19] and West et al. [23] do not include $\mathrm{CO}_{2}$ flux from soil respiration or photosynthesis in determining the GHG flux as this carbon is typically accounted for by determining soil carbon stocks and estimates of standing biomass. $\mathrm{CO}_{2}$ and $\mathrm{N}_{2} \mathrm{O}$ flux can be measured directly in the field or estimated from the literature. Guidelines and esti- 
mates have been produced by a variety of sources. Current estimates of emissions from fuel consumption can be found on the Environment Canada website (http://www.ec.gc.ca/gesghg/default.asp?lang=En\&n=AC2 B7641-1\#section2). Long term GHG flux can be determined using the eddy covariance method [24, 25] with appropriate sensor technology. However, this methodology is expensive and requires significant expertise. A modeling approach is typically employed and several simple to use applications are available (e.g. GREET, Greenhouse Gases, Regulated Emissions and Energy use in Transportation). The IPCC employs a standard methodology for estimating $\mathrm{N}_{2} \mathrm{O}$ emissions in agroecosystems where accurate measurements are not available. [26] provides a critical review of this methodology.

Establishing a critical value for a sustainability index must include estimates of the GHG's emitted during transportation, processing and burning, all of which occur beyond the farm gate. Determining the amount of GHG's fixed, as carbon equivalents $\left(\mathrm{C}_{\mathrm{eq}}\right)$, may be estimated from values published in the literature [27] or via growth curve equations $[28,29]$.

\section{Air Quality}

McBride et al. [19] suggest 4 indicators of air quality: carbon monoxide $(\mathrm{CO})$, tropospheric ozone $\left(\mathrm{O}_{3}\right)$, inhalable particulate matter (PM10) and repairable particulate matter (PM2.5). However, they go on to state that most of these emissions occur with combustion of the biomass. There would be some contributions of these air quality indicators made during cultivation, planting and harvesting. However, these would be minor in comparison. Europe has imposed stringent values on particulate matter emissions with airborne concentrations not to exceed $50 \mu \mathrm{g} \mathrm{m}^{-3}$ and $25 \mu \mathrm{g} \mathrm{m}^{-3}$ for PM10 and PM2.5, respectively.

The challenges related to measurement of GHGs are that the equipment needed for these measurements are very costly and it may not be feasible to measure them and maintain sustainable emission levels by common landowners or growers. Further, GHG emissions are also highly seasonal and weather dependent. Therefore, best management practices that contribute directly towards GHG emission reductions and practices that enhance GHG sequestration should be promoted at the landscape level.

\section{Environmental Soil Indices}

\section{Soil Nitrogen}

Biomass production is greatly influenced by soil nitrogen as it contributes to above ground growth. In this context, [19] suggest total soil nitrogen as a good indicator to assess site quality. Therefore, a measure of total $\mathrm{N}$ (organic and inorganic) would provide a measure of soil productivity over time. Where initial stocks of $\mathrm{N}$ are low, increasing values over time will suggest a move towards a more sustainable system. In a willow biomass production under tree-based intercropping system in southern Ontario, Canada, [30] have reported that higher biomass yields were obtained with only $15 \mathrm{~kg}$ nitrate $\mathrm{N} \mathrm{ha}^{-1}$, released from decomposing leaf litter and fine root biomass turnover. This suggests that willow biomass crop can be grown without external inorganic fer- tilization at least during the initial years of establishment. Therefore, when biomass is produced under an agroforestry system, cycling of nutrients may contribute towards the accumulation of soil $\mathrm{N}$ over time.

However, conversion of lands from one productive, and nitrogen conserving system, to biomass production (which is assumed to have $\mathrm{N}$ conserving properties) may result in an overall reduction in total $\mathrm{N}$. This should not be interpreted as biomass production being unsustainable. There are no critical limits published for total N. Thus, this indice is somewhat subjective in nature and would require careful interpretation specific to individual sites. What is certain is that large decreases in total $\mathrm{N}$ measured over time indicate a decrease in long-term productivity, therefore, may increase the demand for exogenous inputs, a trend towards unsustainability.

\section{Phosphorus}

Phosphorus, similar to nitrogen, is required in relatively large amounts to sustain crop productivity. As it is relatively immobile in soils, $\mathrm{P}$ loss is due to exportation with the crop and soil erosion. Depletion of $\mathrm{P}$ in the soil can significantly decrease yield and deposition of soil bound $\mathrm{P}$ in fresh waters can lead to eutrophication. Thus, conserving and protecting $\mathrm{P}$ stocks in the soil are vital to long term sustainability and this has been suggested as a suitable indicator by [19]. Once again, the literature does not suggest a specific threshold value for soil phosphorus. Methods for measuring extractable phosphorus can be found in [31].

In all biomass production systems, especially in the temperate region, nutrient additions via litterfall, stemflow and throughfall should be quantified against the exportation of nutrients via biomass harvest in order to maintain the nutrient balance of the production system [30].

\section{Total Organic Matter}

It is well documented that changes in land use practices and cultural methods have a strong influence on soil carbon stocks [27, 32]. Soil organic carbon (SOC) or Soil Organic Matter (SOM) has a large influence on a number of soil physical and chemical characteristics including cation exchange capacity (CEC), bulk density, permeability, structure as well as being positively correlated with soil health and quality. Building soil carbon stocks addresses the issues of maintaining and enhancing soil productivity thus ensuring a stock of natural capital for future generations. Growing biomass crops does not assure an increase in SOC. This will depend on previous land use and changes in the biophysical characteristics of the site related to these changes as well as climate change. Additionally, it may be useful to partition SOC into labile and recalcitrant pools. Methods for accounting soil carbon are detailed in the IPCC Guidelines Report no. 3 [33]. Methods for the characterization of SOM can be found in [34].

\section{Erosion}

Soil erosion is a natural process. Enhanced rates of erosion are associated with conventional agronomic practices. Where the rate of soil formation equals or exceeds the rate of erosion, the system can be assessed as sustainable. Alternatively, soil erosion rates can be categorized as suggested in [35]. 
Rates of erosion may be measured directly or approximated through the use of the Revised Universal Soil Loss Equation (RUSLE) [35].

$\mathrm{A}=\mathrm{R} \times \mathrm{K} \times \mathrm{L} \times \mathrm{S} \times \mathrm{C} \times \mathrm{P}$

Where $\mathrm{A}$ is the estimated annual soil loss $\left(\mathrm{T} \mathrm{ac}^{-1}\right.$ or $\left.\mathrm{T} \mathrm{ha}^{-1}\right)$

$\mathrm{R}$ is rainfall factor

$\mathrm{K}$ is the soil erodibility factor

$\mathrm{L}$ is the slope length

$\mathrm{S}$ is the percent slope

$\mathrm{C}$ is the crop coefficient factor

$\mathrm{P}$ is the support practice factor

The support practice factor refers to methods of conservation tillage, planting schemes and/or terracing of slopes. As such, it is likely not applicable to current SRWC planting schemes and can either be ignored or set to a value of ' 1 '. In an agroforestry land-use design, one could use the buffers or shelterbelts as a modifier for factors "L" or slope length. If planted across a slope, this could effectively reduce the slope effect.

The limitation to using the RUSLE is that there are no crop coefficients for SRWC or other proposed biomass crops other than for canary grass (Phalaris canariensis) used as part of a fallow system in the Prairies. There is a crop coefficient for woodlands but this value is for mature woodlands and reflects much different conditions of structure and soil stability than would be found in SRWC system. It also does not account for harvest cycles or for erosion caused by wind.

Direct measurements of erosion may be considerably more involved. Construction of flumes that accurately define the area for sampling and the installation of measuring and/or sampling devices are costly, require skilled operators and can interfere with farm machinery. Alternatively, erosion pins are inexpensive, easily measured and large numbers can be deployed with minimal investment. These and other options are discussed by [36].

\section{Bulk Density}

McBride et al. [19] also suggest bulk density as a useful measure of soil quality. Bulk density is strongly influenced by management and tillage activities as well as the soil biota including the plants that occupy the site. Reducing bulk density suggests a healthier soil but would be highly correlated with changes in SOM. Similarly, soil aggregate stability or permeability could be used as proxies for the general health of a soil but would also be strongly correlated with SOM. The use of such indicators in combination with a measure of SOM may result in over-weighting a more singular aspect of soil physical properties and their use should be subject to careful interpretation.

\section{Environmental Water Indices}

\section{Water Quality}

The Canadian Water Quality Index [37] has been developed to provide a uniform method of evaluating water quality nationally. This is a composite index that summarizes the results of analysis for a variety of naturally occurring potential contaminants as well as several chemical characteristics of water. Interpretation of the composite values requires some level of experience and skill. Also, sample collection and analysis can be quite costly. However, it does allow for an incomplete set of values while reporting summaries that are comparable across regions. Still, there is no rationale behind establishing a specific output value as a limit for sustainability. Despite the benefits, this index does not appear to be a prime candidate as a sustainability criteria within the context of this work as SRWC receive less or no external fertilizer and agro chemical inputs to the system [30].

\section{Water Availability Index}

A potential indicator of water availability is the Falkenmark Water Stress Indicator [38]. The authors suggest a range of available water volumes on a per capita basis that relate to water security:

$>1700 \mathrm{~m}^{3} /$ per/yr Water scarcity occurs irregularly or locally

1000-1700 Water stress appears regularly

500-1000 Water scarcity is a limitation to economic development and human health

$<500 \quad$ Water scarcity is a main constraint to life

(Adapted from CWSI report http://www.horizons.gc.ca/ doclib/SD/SD_PR_CWSI_web_e.pdf)

The indicator ranges from $0-100$ (values less than 0 are set to 0 and >100 set to 100) according to the equation:

$\mathrm{R}=\left(\mathrm{T}_{\text {(cap) }}-100\right) /(1700-500) * 100$

Where $\mathrm{T}_{(\text {cap })}$ is the total renewable water resource/capita/yr and may include either or both surface and ground water resources.

There may be technical or financial limitations to such an indicator as it requires that information on local water supplies exist in some detail or would need to be collected. This data may not exist, especially where smaller communities rely on local groundwater supplies. However, the Falkenmark indicator is perhaps the most widely used method internationally [39].

At the least, groundwater can be monitored for trends in availability. Where a change in land use practice causes a continuing trend in depletion of ground water, this could well be deemed unsustainable. It should be noted that the current land use practices may have caused changes in groundwater levels beyond some unknown sustainability threshold. Such a limit would have to be evaluated on a case by case (farm by farm) basis. Perhaps a lower limit can be arbitrarily established.

In the case of a farm water supply being derived from a shallow (dug) well, if there have been no reported shortages in supply then whatever level of groundwater exists is sustainable as long as demand does not increase. Climate fluctuation (from local to global scale) may influence rates of loss (evapotranspiration) and recharge (rainfall, snowmelt). Short-term trends that may result in occasional water shortages do not necessarily lead to a conclusion of unsustainability. 
Another approach to assessing sustainable water supply is proposed by [40]. Here it is proposed that variability of run-off water (not infiltrated into the soil) indicates vulnerability to drought and flood. In general, soil health is implicated in this indice. Reduction in bulk density, improvement in structure (presence of macropores and development of peds), increase in organic matter content, physical barriers to surface flow may all be attributable to a change from annual crops to perennial crops (SRWC).

This is calculated according to the formula

$\mathrm{R}=(1-(\mathrm{x}-1) / 5-1))^{*} 100$

With $\mathrm{x}=$ runoff ratio. Scores $>100$ are set to 100 and $<0$ are set to 0 . A value 50 or less suggests vulnerability.

The simplest method for monitoring water availability may be to use piezometers. These are simply tubes, open at the bottom and covered with a filter sock, installed in the ground to a depth that corresponds with the groundwater table. The water flows into the tube and sits at a height exactly that of the groundwater. A dipstick or other measuring device is simply lowered into the tube and the depth of the water can be established. Additionally, samples can be collected for chemical and biological analysis.

\section{Nitrate}

Health Canada [41] has established a maximum acceptable concentration (MAC) of nitrate in potable water of 10 $\mathrm{mg} \mathrm{L}^{-1}$ as nitrate-nitrogen. Additionally, Health Canada has established a MAC of $3.2 \mathrm{mg} \mathrm{L}^{-1}$ for nitrite. Both nitrate and nitrite are associated with soil nitrogen transformations, are water soluble and mobile in the soil environment and can be expected to be influenced by changing land use practices. Thus, sampling the water table for changes in nitrate and nitrite should prove to be an effective indicator.

At the pilot scale, monitoring changes in surface water characteristics would be impossible. Surface water run-off can be captured and analyzed.

\section{Biological Oxygen Demand and Chemical Oxygen Demand}

Biological oxygen demand (BOD) and chemical oxygen demand (COD) are common methods of evaluating water quality. BOD can be related to the nutrient load within the water while COD can be used to evaluate the quantity of organic compounds.

\section{Environmental Biodiversity Indices}

\section{Biodiversity Index}

It is widely accepted that increasing biodiversity enhances stability and resilience within an ecosystem. Higher redundancy in an ecosystem, or more specifically within guilds, should result in greater stability [42]. Creating a more complex landscape mosaic, in this case by introducing a new agronomic crop, should create opportunities for greater biodiversity. However, there does not exist a critical value above or below which ecosystem collapse is inevitable or considered likely.
If the farm ecosystem is functioning well, indeed a very subjective determination, prior to the introduction of the biomass crop, a measure of the current diversity may be considered as the threshold value. A caveat to this approximation is that if a keystone or invasive species is present, their contribution to any measure of diversity may be quite small while their true ecological influence may be great.

\section{Soil Biota Index}

There are a variety of methods available to measure soil biological activity, diversity and biomass. A thorough review of current methods and their application can be found in Microbiological methods for assessing soil quality [43]. Several challenges exist in using any of these methods, on their own or in some combination, to assess sustainability. Different soil types have different native biota. Regional climatic differences will also influence things. There is no evidence of a specific value for sustainability. Again, we can compare results between similar soils under different management practices. In work reported by [43] the reference soil was sourced from an organic farm.

\section{Economic Indices}

\section{Microeconomic Indicator}

Microeconomic sustainability ranked high in the survey by [15]. However, [44] identifies the many challenges in developing economic indicators due to the variety of attributes that contribute to farm viability, not the least of which is the time factor and the associated unpredictability of variables that influence rates of return on investment (e.g. weather, interest rates, market demand). SRWC have harvest rotations of 3 or more years. The further into the future we attempt to predict the less certain we are of our accuracy.

Tisdell [44] suggests that, while not an ideal indicator, net present value (NPV) is the most easily obtained and comprehensive value available. NPV is calculated as

\section{$\sum \mathrm{R}_{\mathrm{t}} /(1+\mathrm{i})^{\mathrm{t}}$}

Where $R_{t}$ is the net cash flow (inflow - outflow)

$i$ is the discount rate (the rate of return on an alternative investment with similar risk) and $\mathrm{t}$ is time.

Given the uncertainty associated with predicting NPV, it would be wise to use conservative values in determining the discount rate. Calculating the outflow portion of $R_{t}$ is relatively straightforward. Bioenergy plantations have capital costs that are largely frontloaded (high start up cost and low maintenance costs) removing some of the uncertainty associated with long term financial planning. However, the inflow projection will be dependent on productivity and the estimated price for the crop. Some of this uncertainty can be eliminated if contracts with set prices for the crop are maintained.

While using NPV is standard accounting practice and is quite simple where most costs are internalized, agriculture in general possesses many externalities, both positive and negative. A full accounting of ecosystem goods and services as well as the negative externalities should be included if possible. It is generally assumed that SRWC, as well as other bio- 
energy crops, will enhance ecosystem and environmental qualities while reducing negative impacts.

Where the NPV is greater than zero the system may be said to be sustainable.

\section{On-Farm Employment}

The creation of revenue generating employment opportunities for members of the farm family can contribute to economic and social well being. However, even where more revenue can be realized the timing or volume of the workload may conflict with other required farm duties or other necessary or desirable tasks including educational and recreational opportunities.

The direct benefit of added income suggests a system that is more sustainable and can be easily measured. If family members are in a better financial position year after year then the system may be deemed sustainable. But, not if this benefit comes at a physical or emotional cost.

The distribution of workload can influence the physical and emotional health of farm labourers. This is a more difficult thing to measure and there are no metrics discussed in the literature. Developing an index may require both a quantitative and qualitative assessment of the individuals involved in the work. A qualitative assessment can be achieved by logging hours worked on a daily basis on specific tasks or chores. Thus, workloads can be compared either in a before and after scenario or side-by-side where other farms of similar size and structure are available for comparison.

The second component would require a survey of individual workers where they would self assess their physical and emotional attributes compared to an initial assessment prior to the introduction of the bioenergy crop.

\section{Social Indices}

This pillar of sustainability is typically measured at a larger scale than can easily be evaluated for small-scale changes in land use. As such, there is a requirement to develop new indices. The relative lack of social indicators dis- cussed in the literature is an indication of the difficulty in developing an indicator that meets the 6 criteria discussed earlier. It is likely that some potential indicators of social sustainability may be challenged due to cultural or personal bias.

At a minimum, we may accept the human rights charter established by the United Nations as a basis for creating social indicators. However, it is difficult to establish a direct link between these established rights and what amounts to a minor shift in agronomic practices. Thus, the validity of the criteria is tenuous at best.

Buchholz et al. [15] identify 15 social indicators of sustainability in their survey. Of these, only 2 ranked in the top 10, 'participation' and "compliance with laws". Within the Canadian context, and constrained by the farm boundary, the latter indices is not likely to be discriminatory. That is, all farms would likely be in compliance with laws in growing biomass providing they follow 'good' or 'best' management practices. The former, sometimes stated as participatory democracy, is almost universally accepted in the literature as necessary for a sustainable system. This can be evaluated through simple survey questions at various stages of the production cycle and by maintaining good records (i.e. attendance to stakeholder meetings, minutes of planning meetings).

\section{Visualizing and Interpreting the Data}

In order to summarize all the above discussed indices, we suggest that a common method of visualizing the data related to above indices is to generate amoeba diagrams [45] (Fig. 1). These are 2-dimensional, multi-axis diagrams where the axis scale can be ordinal or relational. Using relational axes makes visual interpretation easier. In the absence of distinct values (or ranges of values) that are deemed thresholds of sustainability, data can be normalized against a reference state. The reference state may be determined by collecting information from a local site that reflects an ideal state of the ecosystem. This could be a site that has minimal disturbance and native vegetative cover, or farmland that is currently

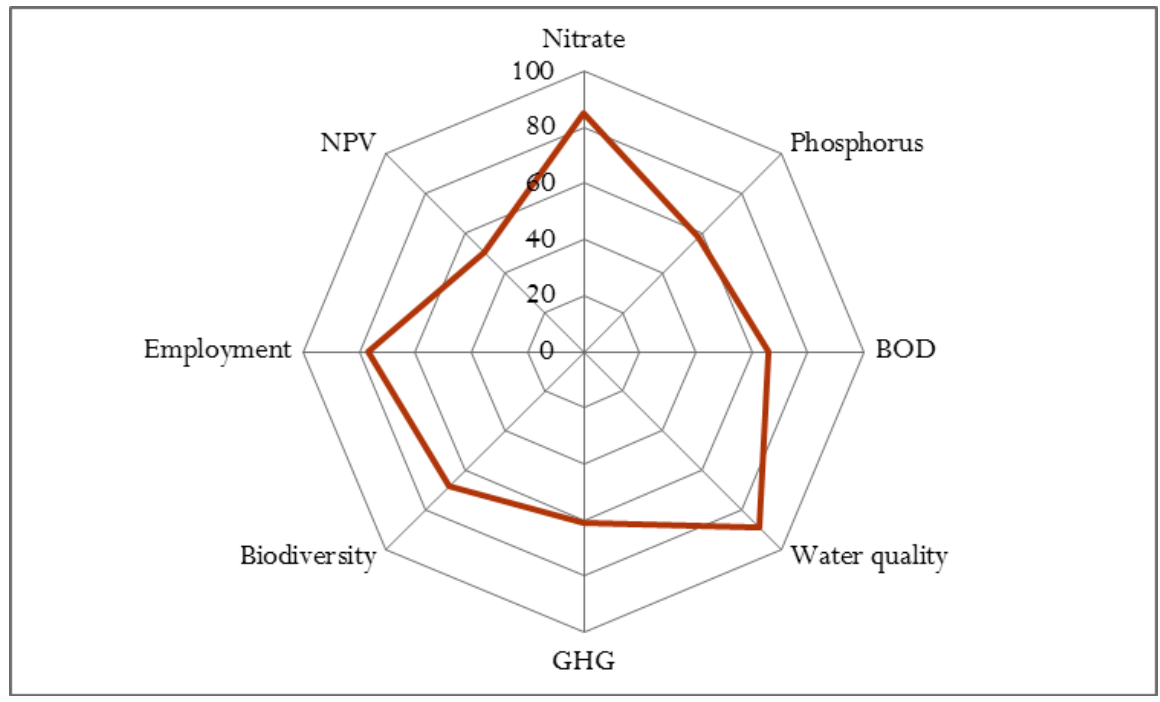

Fig. (1). Example of an amoeba diagram. From Bell and Morse (2000) [NPV- Net Present Value; BOD - Biological Oxygen Demand; GHG - Greenhouse Gas]. 
managed under the best management practices.

Amoeba diagrams do not provide a composite value for sustainability. They are a visual representation that effectively gives equal weight to each index that will allow for comparison and interpretation. Collecting the same set of data on the sustainable indicators over time, the user can see which areas are improving, which are declining while still getting a sense of the overall sustainability of the system.

\section{CAVEATS}

The suite of indicators proposed here may not be comprehensive. Our understanding of the intricacies of the biophysical environment, shifting economic theories and social changes may alter our intrinsic understanding of some of the proposed indicators. Scale, both spatially and temporally, may also contribute to a shifting emphasis towards specific indicators or the creation of new ones. Ultimately, there will be a need to co-ordinate any set of indicators with international standards to facilitate the incorporation of local information into larger models (e.g integrated modelling and assessment) appropriate for policy development and hypothesis development (further academic inquiry).

\section{AGROFORESTRY SYSTEMS}

Agroforestry is an approach to land-use that incorporates trees into farming systems, and allows for the production of trees and crops or livestock from the same piece of land in order to obtain economic, ecological, environmental and cultural benefits [16]. Agroforestry has its roots in the developing world, where lack of land resources in the presence of high population growth necessitated the development of novel and simultaneous wood and food production systems by indigenous peoples. In North America and in Canada, many different types of agroforestry have been employed historically [16], but the vast potential for economic and environmental benefits attributed to agroforestry have yet to be realized on a large scale. The main types of agroforestry practices currently being researched in many areas of Canada are shelterbelts and windbreaks, silvopastoral systems [animals, pasture and trees], integrated riparian forest systems, forest farming systems, and tree-based intercropping systems [crops grown between widely spaced tree rows]. Three agroforestry systems that have the greatest potential to produce biomass are: shelterbelt, intercropping and riparian plantings [30]. Therefore, within the context of biomass production potentials, these agroforestry systems, will be discussed as to how these systems can promote above indicated sustainability indices.

\section{Shelterbelt}

Shelterbelt systems, primarily appropriate to western Canada, may include multi-row and multi-species arrangements of trees. Including SRWC into such systems may be feasible from an agronomic standpoint. Economic feasibility will require estimates of increased annual crop yield per unit area attributable to the shelterbelt, annual yield lost due to lands committed to the shelterbelt and the net present value of the SRWC. Harvest cycles could be staged to ensure the performance of the shelterbelt is not greatly diminished. This could well be managed to maintain the height and porosity of the shelterbelt as well as benefits associated with habitat, biodiversity, GHG sequestration, etc. Under drier conditions typical of the prairies, poplar is preferred and rotation length may be in the order of 7-10 years. In more humid climates hybrid willow may be incorporated and shorter rotations are possible.

Two general design options are viable. The first would include 1 or 2 rows of long-lived evergreens (spruce, pine) with several rows of SRWC species. The second may consist of only SRWC but to maintain the beneficial effect of modifying wind patterns shelterbelts would be closely spaced. [46] suggest the distance between shelterbelts of 10-15 times the expected height at harvest age. With either design, the width of the planting should be a multiple of the width of the equipment used for planting and/or harvesting and also should accommodate land that will be occupied by the growth of trees in the rows. As harvesters are typically quite specialized, and more expensive to operate, this is likely the overriding consideration in planning the width in addition to spray boom width.

The proposed suite of sustainability indicators, discussed in relation to SRWC systems, may not all be appropriate for assessing a system such as this. Shelterbelts are typically designed to optimize soil protection and enhance conditions for crop growth. As such, their influence on open waters may be negligible but may contribute positively to reduce surface overflow or run off. However, they may influence ground water reserves (quantity) and use of fertilizers and crop protection products (quality). Monitoring changes in ground water would be of great importance. Shelterbelts designed to address habitat fragmentation as well as crop protection may result in increased observations of species of special interest (e.g. locally identifies species at risk). While such observations would be factored in to any measure of biodiversity, their presence or absence may be given special weight in the overall assessment of sustainability.

Shelterbelts designed for the sole purpose of odour and/or dust reduction to enhance the air quality have to be placed around livestock production facilities or closer to the farm production facilities. Four primary factors are thought to contribute to these odour issues: a) urban expansion and housing development closer to farming communities, b) increased production and application of manure to soils, c) long range transportation of odour due to lack of vegetative barriers, d) current municipal policies have limited producer incentives to control activities beyond minimum regulatory requirements [47]. Shelterbelts are also being used as sound barriers contributing to acceptable noise levels for a healthy living. In this context, sound levels of $66 \mathrm{dBA}$ and $50 \mathrm{dBA}$ have been recommended as acceptable daytime and nighttime sound levels, respectively. These numbers can be considered as an acceptable indicator for sound as influenced by shelterbelts. However, there are no defined sustainability indicators related to shelterbelts and air quality at the present time, therefore, development of such indicators in relation to shelterbelt designs should be considered in the future.

\section{Intercropping}

SRWC may also be incorporated into an intercropping system where either SRWC are grown as an understory crop within a timber plantation or intercropped with other tradi- 


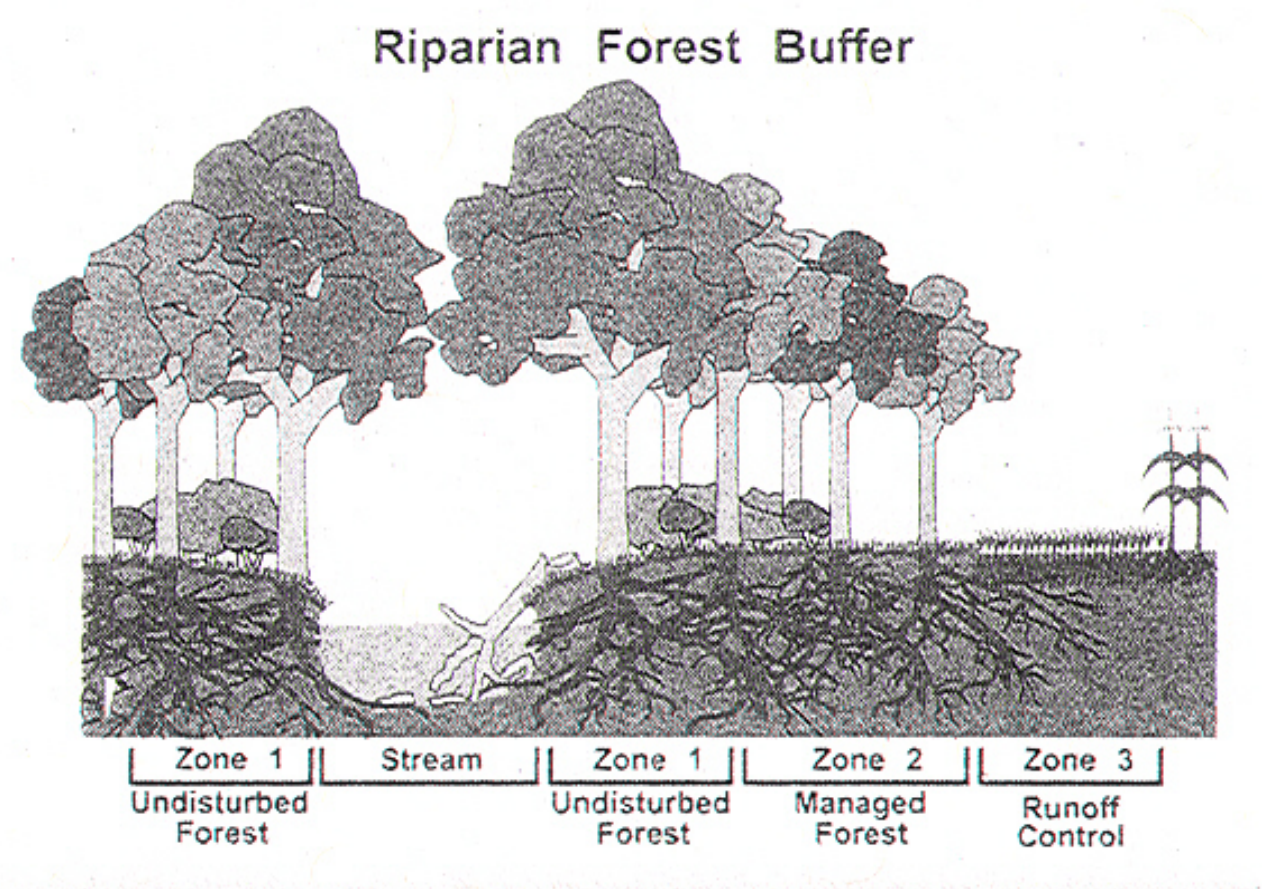

Fig (2). Generalized riparian forest buffer design. Adapted from Welsch (1991).

tional annual crops (e.g. corn (Zea mays), soybean (Glycine max), winter wheat (Triticum aestivum)) with or without the timber component [48] state that block plantings of SRWC are more economically efficient; however, greater environmental gains can be achieved through methods of stripcropping. On sloping land, contour plantings would provide additional gains in reducing soil erosion. The benefits of such a system are similar to those observed in other systems incorporating a perennial component and include enhanced nutrient cycling, improved soil structure, greater biodiversity, reduced erosion and evaporative loss of water.

As with the shelterbelt design, the width of the SRWC strip should be a multiple of the width of the available machinery. The width of the annual crop strips would also be determined by the available machinery but on lands susceptible to erosion, the crop widths may also be determined by applying the revised universal soil loss equation. In effect, strip cropping creates many small fields and reduces the potential for excessive soil movement. The choice of species and rotation length of the SRWC component will be influenced by soil and site conditions as well as consideration for competition, especially for light. Long rotation cycles of single stemmed woody crops may result in unacceptable reductions in annual crop yield due to shading. Shorter rotations of coppiced trees will reduce light competition. Combined with appropriate tillage along the SRWC margin, both above and belowground competition can be managed.

Intercropping with SRWC can reasonably be expected to create a number of environmental benefits including increased biodiversity, reduced GHG emissions, enhanced carbon sequestration at the system level, increased soil organic matter and enhanced water conservation [49]. It can also distribute workloads over a greater period of time, which may be perceived by the practioner as a benefit and may enhance economic returns. Economic returns can be determined by applying standard accounting methods. Measures of workload and personal satisfaction may best be determined via a standardized survey. Measuring the environmental changes is somewhat more complex.

There will exist greater diversity of environmental characteristics in an intercropped field. These zones will have to be taken into careful consideration when sampling or measuring for some of the proposed sustainability indicators [49] summarize the results of a number of studies conducted at the University of Guelph Agroforestry Research Station, a 30 ha intercrop plantation. In this summary, the authors note distinct differences in soil carbon between tree rows and the alleys with annual crops. There is also a transition zone between the tree and crop alleys that is a function of the height of the trees, which results in non-uniform distribution of leaf litter and fine root turnover across the field. Sampling for soil properties, whether chemical or physical, will require a methodology appropriately weighted to the area of land under the different crops.

Intercropping introduces structural diversity to the landscape, not just horizontally but vertically as well. This may make direct measurement of some indices more difficult (e.g. GHG's), which suggests that generating estimates from models or from data mining the literature will be more practical. Other indices may still be directly measured in the field but due to the increased complexity of the system, a proxy may need to be used. For example, biodiversity changes would require extensive sampling. Substituting birds alone as a measure of diversity may be acceptable and has already been shown to be demonstrably different under this management system [50].

\section{Riparian Zone Plantings}

Afforested riparian zones may include SRWC as a component of the system where the primary goals are to protect 
soil and water quality. Such a system would include trees, grasses and shrubs (Fig. 2). At the field margin cool season grasses are grown to intercept soil particles and slow water movement. At the water interface larger trees are grown to provide permanent streambank stability as well as to shade the water resulting in reduced temperatures and decreasing the potential for excessive algal growth. Between these zones SRWC may be grown providing several ecological and environmental benefits. These benefits include increased infiltration of surface waters, enhanced trapping of sediment and potential pollutants (nutrients, pesticide residue, E. coli), enhanced wildlife habitat, reduced flooding potential, etc. Harvest cycles would temporarily diminish some of these benefits but the permanent root systems would continue to provide important benefits.

Kuhn and Rietveld [48] summarizes the work of the US Natural Resources Conservation Service (NRCS) and provide suggested minimum widths for SRWC production in riparian zones (Fig. 2). Nearest the water a 15 foot $(4.5 \mathrm{~m})$ zone is reserved for native tree species. A minimum 20 foot $(6 \mathrm{~m})$ zone is required for SRWC production, and an optional 15 foot $(4.5 \mathrm{~m})$ grassed zone at the cropped field margin. This zone is optional based on the landowners objectives and need for a filter to slow rates of run-off and filter sediment. A site with relatively level topography and/or a soil with low water erosion potential would benefit less from a grass strip. The middle zone can be made wider depending on landowner objectives and an objective valuation of at least the economic and environmental benefits of the system.

Afforested riparian zones in agricultural settings are specifically designed to protect surface waters. As such, the sustainability indices employed to monitor this system would be more heavily weighted towards water quality issues. In addition to the proposed suite of sustainability indicators, other characteristics could be monitored as measures of ecosystem change. How these changes are evaluated, as positive, negative or neutral, will require interpretation relevant to the specific site. The list of in-stream characteristics that could be monitored includes temperature, turbidity, dissolved oxygen, conductivity, type and distribution of substrate and bank stability. These indicators would be most suitable for assessing stream quality as habitat for specific species that are most sensitive to such changes (e.g. trout (Salvelinus fontinalis)). Most of the proposed indicators do not have an absolute threshold for sustainability. As such, ecosystem changes must be evaluated over time and with respect to the stated goals. Generating a complete characterization of the site and waterway prior to changing management systems would be required to fully assess the effect of the ecosystem changes.

\section{CONCLUSION}

It is demonstrated that agroforestry systems have better economic, social and environmental benefits than conventional agriculture. These benefits include increased farmer income, enhanced habitat, biodiversity, GHG sequestration, more efficient nutrient cycling, increased infiltration of surface waters, enhanced trapping of sediment and potential pollutants, etc. This study has attempted to provide a review of the key organizations involved in developing methodolo- gies for assessing and evaluating sustainability for bioenergy projects. However, most of the proposed indicators examined here may not be comprehensive. In this context, the Visualizing and Interpreting the Data method (Fig. 1) could be a useful tool for assessment, but it does not provide a composite value for sustainability. To summarize, in order to have an effective assessment of sustainability indicators associated with any biomass production system, international standards should be established to facilitate sustainable system designs, which can be implemented under specific site conditions.

\section{CONFLICT OF INTERESTS}

The authors confirm that this article content has no conflicts of interest.

\section{ACKNOWLEDGEMENTS}

The authors sincerely acknowledge the funding received from Agriculture and AgriFood Canada (AAFC) for this work.

\section{REFERENCES}

[1] Jose S. Agroforestry for ecosystem services and environmental benefits: an overview. Agrofor Syst 2009; 76: 1-10.

[2] Nair PKR. Agroforestry systems and environmental quality: introduction. J Environ Qual 2011; 40: 784-90.

[3] Fortune J, Hughes J. Modern academic myths. In: Armson R, Holloway J, Jackson S, McRobb S, Eds. Systems for sustainability: People, organizations and environments. New York and London: Plenum Press 1997; pp 125-30.

[4] UN. Our common future. 1987; Available at: http://www.undocuments.net/ocf-02.htm

[5] Schaller N. Low input sustainable agriculture. In: Smith DT (ed) Yearbook of agriculture: Farm management. USDA Washington D.C, 1989; pp. $216-9$.

[6] Allen P, Van Dusen D, Lundy L, Gliessman S. Integrating social, environmental and economic issues in sustainable agriculture. Am J Alternat Agric 1991; 6:34-9.

[7] Ainsworth E. LISA men have called you. Farm J 1989; 113

[8] Sharma D, Shardendu S. Assessing farm level agricultural sustainability over a 60-year period in rural eastern India. Environmentalist $2011 ; 31: 325-37$.

[9] Pearce D, Markandya A, Barbier E. Blueprint for a green economy. Earthscan. London, 1989.

[10] Smith CS, McDonald GT. Assessing the sustainability of agriculture at the planning stage. J Environ Manage 1998; 52:15-37.

[11] Hartmuth G, Huber K, Rink D. Operationalization and contextualization of sustainability at the local level. Sustain Dev 2008; 16: 261-70.

[12] Hilden M, Rosenstrom U. The use of indicators for sustainable development. Sustain Dev 2008; 16: 237-40.

[13] Zahm F, Viaux P, Vilain L, Giardin P, Mouchet C. Assessing farm sustainability with the IDEA method - from the concept of agriculture sustainability to case studies on farms. Sustain Dev 2008; 16:271-81.

[14] Landais E. Agriculture durable: les fondements d'un nouvau contrat social. Courier de l'environnement de l'INTRA 1998; 33:5-22.

[15] Buchholz T, Luzadis VA, Volk TA. Sustainability criteria for bioenergy systems: results from an expert survey. J Clean Prod 2009; 17:586-98.

[16] Gordon AM, Newman SM, Williams PA. Temperate agroforestry: an overview. In: Gordon, AM, Newman SM, Eds. Temperate Agroforestry Systems. Wallingford, UK: CAB International Press, 1997; pp 1-8.

[17] Garrett, HE, Rietveld W, Fisher JF, Kral DM, Viney MK. North American Agroforestry: An Integrated Science and Practices. Madison, Wisconsin: American Society of Agronomy, 2000.

[18] Thevathasan NV, Gordon AM, Simpson, JA, Reynolds, PE, Price GW, Zhang P. Biophysical and ecological interactions in a temper- 
ate tree-based intercropping system. J Crop Improv 2004; 12: 33963.

[19] McBride AC, Dale VH, Baskaran LM, et al. Indicators to support environmental sustainability of bioenergy systems. Ecol Indic 2011; 11:1277-89.

[20] Brandāo M, Mila L, Canals I, Clift R. Soil organic carbon changes in the cultivation of energy crops: Implications for GHG balances and soil quality for use in LCA. Biomass Bioenerg 2011; 35:232336.

[21] Qin Z, Zhuang Q, Zhu X, Cai X, Zhang X. Carbon consequences and agricultural implications of growing biofuel crops on marginal agricultural lands in china. Environ Sci Technol 2011; 46:1076572 .

[22] Gasol CM, Gabarrell X, Anton A, Rigola M, Carrasco J, Ciria P, Rieradevall J. LCA of poplar bioenergy system compared with brassica carinata energy crop and natural gas in regional scenario. Biomass Bioenerg 2009; 33:119-29.

[23] West TO, Brandt CC, Baskaram LM, et al. Cropland carbon fluxes in the United States: increasing geospatial resolution of inventorybased carbon accounting. Ecol Appl 2010; 20:1074-86.

[24] Baldocchi DD. Assessing the eddy covariance technique for evaluating carbon dioxide exchange rates of ecosystems: past, present and future. Glob Change Biol 2003: 9: 1-14.

[25] Clement RJ, Burba GG, Grelle A, Anderson DJ, Moncrieff JB. Improved trace gas flux estimation through IRGA sampling optimization. Agricultural and forest meteorology 2009; 149: 623-38.

[26] Nevison C (Undated) Available at: http://www.ipccnggip.iges.or.jp/public-/gp/bgp/4_6_Indirect_N2O_Agriculture.pdf.

[27] Peichl M, Thevathasan NV, Gordon AM, Huss J, Abohassan RA. Carbon sequestration potentials in temperate tree-based intercropping systems, southern Ontario, Canada. Agrofor Syst 2006; 66:244-57.

[28] Amichev BY, Johnston M, Van Rees KCJ. Hybrid poplar growth in bioenergy production systems: Biomass prediction with a simple process-based model (3PG). Biomass Bioenerg 2010; 34:687-702.

[29] Valentine HT, Tritton LM, and Furnival GM. Subsampling trees for biomass, volume or mineral content. For Sci 1984; 30:673-81.

[30] Cardinael R, Thevathasan N, Gordon A, Clinch R, Mohammed I, Sidders D. Growing woody biomass for bioenergy in a tree-based intercropping system in southern Ontario, Canada. Agrofor Syst 2012; 86: 279-86.

[31] Fixen, PE, Grove JH. Testing soils for phosphorus. In: Westerman RL, Ed. Soil testing and plant analysis. $3^{\text {rd }} \mathrm{ed}$. Madison: Wisconsin, SSSA, 1990; pp141-80.

[32] Ogle SM, Breidt FJ, Paustian K. Agricultural management impacts on soil organic carbon storage under moist and dry climatic conditions of temperate and tropical regions. Biogeochemistry 2005; 72:87-121.

[33] IPCC. Revised 1996 IPCC guidelines for national greenhouse gas inventories: Reference Manual (vol. 3). In: Houghton JT, Meira LG, Filho LG, Eds., Intergovernmental Panel on Climate Change. United Kingdom: Bracknell 1997.

[34] Swift RS. Organic matter characterization. In: Sparks DL, ed. Methods of soil analysis Part 3 Chemical methods. SSSA book series 5. Madison Wisconsin USA: 1996; pp 1011-69.
[35] Wall GJ, Coote DR, Pringle EA, Shelton IJ. RUSLEFAC - Revised Universal Soil Loss Equation for Application in Canada: A Handbook for Estimating Soil Loss from Water Erosion in Canada. Research Branch, Agriculture and Agri-Food Canada. Ottawa, 2002. Contribution: AFC/AAC2244E. Available at: http://sis.agr.gc.ca/cansis/publications/manuals/2002-92/ruslecan.pdf.

[36] Hudson NW. Field measurement of soil erosion and runoff. FAO, Rome, 1993. Available at: http://www.fao.org/docrep/T0848E/T0848E00.htm.

[37] CCME (Canadian Council of Ministers of the Environment). Canadian water quality guidelines for the protection of aquatic life: CCME Water Quality Index 1.0, Technical Report. In: Canadian environmental quality guidelines, 1999, Canadian Council of Ministers of the Environment, Winnipeg, 2001.

[38] Falkenmark, MJ, Lundqvist J, Widstrand C. Macro-scale water scarcity requires micro-scale approaches: aspects of vulnerability in semi-arid development. Nat Resour Forum 1989; 13:258-267.

[39] Brown A, Matlock MD. A review of water scarcity indices and methodologies. Food, beverage and agriculture, White paper 2011; 106.

[40] Gleick, PH. Vulnerability of water systems. In: Waggoner PE (Ed) Climate change and the US water resources. New York: John Wiley and Sons, 1990; pp. 223-40.

[41] Health Canada. 1987; Available at: http://www.hc-sc.gc.ca/ewhsemt/pubs/wat-er-eau/nitrate_nitrite/index-eng.php

[42] Isbell FV, Calcagno A, Hector J, et al. High plant diversity is needed to maintain ecosystem services. Nature 2011; 477: 199-202.

[43] Bloem J, Schouten AJ, Sorensen SJ, Rutgers M, van der Werf A, Breure AM. Monitoring and evaluating soil quality. Pp 23-49. In: Bloem J, Hopkins DW, Benedetti A, Eds. Microbiological methods for assessing soil quality. CAB International, 2006; pp. 23-49.

[44] Tisdell C. Economic indicators to assess the sustainability of conservation farming projects: An evaluation. Agric Ecosyst Environ 1996; 57:118-31

[45] Bell S, Morse S. Sustainability indicators: measuring the immeasurable. London: Earthscan, 2000.

[46] Josiah SJ, Kuhn G. Planning and design considerations for hybrid poplar timberbelts. Agroforestry notes 21 USDA, Lincoln, Nebraska, 2000.

[47] Tyndall JC, Wallace DC. Windbreaks: A 'fresh' tool to mitigate odors from livestock production facilities. Agroforestry notes 41 USDA, Lincoln, Nebraska, 2011.

[48] Kuhn GA, Rietveld WJ. Opportunities for growing short-rotation woody crops in agroforestry practices. Agroforestry notes 10 USDA, Lincoln, Nebraska, 1998.

[49] Thevathasan NV, Gordon AM. Ecology of tree intercropping systems in the North temperate region: Experiences from southern Ontario Canada. Agrofor Syst 2004; 61: 257-83.

[50] Williams PA, Koblents H, Gordon AM. Bird use of an intercropped maize old fields in southern Ontario. In: Ehrenreich JH, Ehrenreich DL, Eds., In: Proceedings of the Fourth North American Agroforestry Conference 1995, Boise, Idaho, United States, 1995; pp. 15862.

\begin{tabular}{lll}
\hline Received: February 03, 2014 & Revised: March 12, 2014 & Accepted: March 13, 2014
\end{tabular}

(C) Thevathasan et al.; Licensee Bentham Open.

This is an open access article licensed under the terms of the Creative Commons Attribution Non-Commercial License (http://creativecommons.org/licenses/by-nc/3.0/) which permits unrestricted, non-commercial use, distribution and reproduction in any medium, provided the work is properly cited. 